\title{
Interaksi Simbolik Pengajar Musik Tunanetra dengan Siswa Tunanetra di Yayasan Mitra Netra Lebak Bulus Jakarta Selatan
}

\author{
Intan Puspitasari dan Suzy Azeharie \\ intanpuspitasari312@gmail.com,suzya@fikom.untar.ac,id \\ Fakultas Ilmu Komunikasi Universitas Tarumanagara
}

\begin{abstract}
The difficulty of the blind is the limitation in seeing so the need for education that is in accordance with the characteristics and needs. Blind children not only have to get academic education but also non-academic education, so that the potential of children develops optimally. Mitra Netra Lebak Bulus Foundation, South Jakarta teaches expertise outside academic education, one of which is music learning. Has three music instructors who are blind persons with the name of Adi Ariyanto who teaches piano, Suryo Pramono who teaches angklung and Oki Kurnia teaches acoustic guitar. Teaching music for blind children seeks to provide equal opportunities to all children including blind children in obtaining learning opportunities. The purpose of this study was to determine the symbolic interaction of blind music instructors with blind students at the Mitra Netra Lebak Bulus Foundation in South Jakarta. And to find out how the instructors of blind music overcome obstacles in learning music at the Mitra Netra Lebak Bulus Foundation in South Jakarta. The theory used in this study is the theory of communication, verbal communication and symbolic interaction. This study uses a descriptive qualitative approach. The study will use in-depth interviews with five speakers, namely three music instructors, foundation administrators and students. The research data obtained are sourced from interviews, observation and literature. The conclusion of this study is the communication of symbolic interaction between instructors of blind music with blind students at Mitra Netra Foundation is to use repetition of sound through hearing and symbolic interaction in the form of touch. Because it doesn't use visuals because students and instructors are visually impaired. In communicating using symbolic interactions in the form of touch, done by the way the students' fingers are held to follow the movements of the music instructor. After that students must listen and practice learning given by the music instructor.
\end{abstract}

Keywords:Symbolic Interaction, Furnishings, Communication, Blind Music Teachers and Blind Students

\begin{abstract}
Abstrak
Kesulitan tunanetra adalah keterbatasan dalam melihat sehingga perlunya pendidikan yang sesuai dengan karakteristik dan kebutuhannya. Anak tunanetra tidak hanya harus mendapat pendidikan akademik tetapi juga pendidikan non akademik, sehingga potensi anak berkembang secara optimal. Yayasan Mitra Netra Lebak Bulus Jakarta Selatan mengajarkan keahlian di luar pendidikan akademik yaitu salah satunya adalah pembelajaran bermusik. Yayasan ini memiliki tiga orang pengajar musik yang merupakan penyandang tunanetra. Pengajaran bermusik untuk anak tunanetra berupaya memberikan kesempatan yang sama kepada semua anak termasuk anak tunanetra dalam memperoleh kesempatan belajar. Tujuan penelitian ini adalah untuk mengetahui interaksi simbolik pengajar musik tunanetra dengan siswa tunanetra di Yayasan Mitra Netra Lebak Bulus Jakarta Selatan. Untuk mengetahui cara pengajar musik tunanetra mengatasi kendala dalam pembelajaran bermusik di Yayasan Mitra Netra Lebak Bulus Jakarta Selatan. Teori yang digunakan dalam penelitian ini adalah
\end{abstract}


teori komunikasi, komunikasi verbal dan interaksi simbolik. Penelitian ini menggunakan pendekatan kualitatif yang bersifat deskriptif. Penelitian akan menggunakan wawancara mendalam terhadap lima orang narasumber yaitu tiga pengajar musik, pengurus yayasan dan siswa. Data penelitian yang diperoleh bersumber dari wawancara, observasi dan studi pustaka. Kesimpulan dari penelitian ini adalah komunikasi interaksi simbolik antara pengajar musik tunanetra dengan siswa tunanetra di Yayasan Mitra Netra adalah menggunakan pengulangan suara melalui pendengaran dan interaksi simbolik berupa perabaan. Sebab tidak menggunakan visual karena siswa dan pengajar merupakan tunanetra. Dalam berkomunikasi menggunakan interaksi simbolik berupa perabaan, dilakukan dengan cara jari siswa dipegang untuk mengikuti gerak tangan pengajar musik. Setelah itu siswa harus mendengarkan dan mempraktikkan pembelajaran yang diberikan oleh pengajar musik.

Kata Kunci: Interaksi Simbolik, Perabaan, Komunikasi, Pengajar Musik Tunanetra dan Siswa Tunanetra

\section{Pendahuluan}

Tidak bisa dipungkiri terdapat perbedaan di antara manusia, menurut Asep AS. Hidayat dan Ate Suwandi dalam bukunya yang berjudul Pendidikan Anak Berkebutuhan Khusus Tunanetra. Kebanyakan manusia terlahir dalam keadaan normal artinya lahir dengan baik secara fisik, mental dan sosial. Tapi terdapat orang yang lahir tidak sempurna dan kekurangan sehingga nilainya kurang baik atau terlalu baik secara fisik, mental dan sosial. Orang dengan kelainan fisik dapat dikategorikan pada beberapa bagian yaitu berkelainan pada mata, gangguan pada pendengaran, gangguan organ bicara dan cacat organ gerak (Hidayat dan Suwandi, 2016:1).

Dalam bidang pendidikan luar biasa menurut Sutjihati Somantri dalam bukunya yang berjudul Psikologi Anak Luar Biasa seorang dengan gangguan penglihatan disebut tunanetra. Pengertian tunanetra berarti individu yang buta dan individu yang mampu melihat namun terbatas dan kurang dapat dimanfaatkan untuk kepentingan hidup sehari-hari terutama dalam belajar. Akibat dari ketunanetraan maka pengenalan atau pengertian terhadap dunia luar tidak dapat diperoleh secara lengkap dan utuh. Dengan demikian perkembangan kognitif anak maupun orang dewasa dengan penyandang tunanetra cenderung terhambat dibandingkan dengan manusia normal pada umumnya. Hal ini disebabkan perkembangan kognitif tidak saja erat kaitannya dengan kecerdasan atau kemampuan inteligensinya tetapi juga dengan kemampuan indera penglihatannya (Somantri, 2009:67).

Kesulitan anak tunanetra adalah keterbatasan dalam melihat sehingga perlunya pendidikan yang sesuai dengan karakteristik dan kebutuhannya. Anak tunanetra tidak hanya harus mendapat pendidikan akademik tetapi juga pendidikan non akademik, sehingga potensi anak berkembang secara optimal. Yayasan Mitra Netra Lebak Bulus Jakarta Selatan mengajarkan keahlian di luar pendidikan akademik yaitu salah satunya adalah pembelajaran bermusik yang terdiri dari alat musik piano, gitar dan angklung. Pengajaran bermusik untuk anak tunanetra berupaya memberikan kesempatan yang sama kepada semua anak termasuk anak tunanetra dalam memperoleh kesempatan belajar.

Yayasan Mitra Netra memiliki tiga orang pengajar musik yang merupakan penyandang tunanetra bernama Adi Ariyanto yang mengajar piano, Suryo Pramono mengajar angklung dan Oki Kurnia mengajar gitar akustik. Dahulu Oki Kurnia dan Suryo Pramono merupakan siswa di Yayasan Mitra Netra Lebak Bulus Jakarta Selatan sedangkan Adi Ariyanto dahulu magang dan karyawan di Yayasan Mitra Netra. Walaupun pengajar musik terbatas penglihatan namun pengalaman dan 
pengetahuan serta indera pendengaran dan perabaan mereka mampu membantu proses pembelajaran secara maksimal. Dengan kata lain penyandang tunanetra tidak terbatas kemampuannya yang terbatas hanyalah penglihatannya.

Adanya pembelajaran bermusik untuk siswa tunanetra karena musik menurut Ratna Supradewi dalam jurnal Buletin Psikologi yang berjudul Otak, Musik dan Proses Belajar dapat menata suasana hati, mengubah keadaan mental siswa dan mendukung lingkungan belajar untuk merangsang dan mempertahankan lingkungan belajar optimal. Musik dalam proses belajar dapat digunakan untuk meningkatkan semangat, merangsang pengalaman, menumbuhkan relaksasi, meningkatkan fokus, membina hubungan, respon secara emosional, memberi inspirasi dan bersenang-senang (Supradewi, 2010:66). Dengan demikian pembelajaran bermusik memainkan peranan untuk membantu meningkatkan pembelajaran secara optimal di Yayasan Mitra Netra Lebak Bulus Jakarta Selatan.

Tujuan pelayanan anak luar biasa menurut Bernardine R. Wirjana dalam bukunya yang berjudul Pelayanan Sosial Bagi Anak-anak Cacat, adalah memberikan dukungan kepada anak-anak cacat dan keluarga mereka untuk meningkatkan kemampuan anak, membantu anak berkembang sesuai potensi yang dimiliki secara optimal, serta mengurangi stres dan tekanan yang diderita keluarga dalam mengasuh dan merawat anak-anak mereka yang cacat (Wirjana, 2009:35).

Yayasan Mitra Netra yang merupakan pelayanan untuk penyandang tunanetra beroperasi di Gunung Balong Lebak Bulus Jakarta Selatan pada tahun 2002 setelah yayasan ini berumur 11 tahun. Sebelumnya lembaga yang secara konsisten melayani penyandang tunanetra ini masih harus berpindah-pindah dari satu tempat ke tempat lain dikarenakan tidak memiliki tempat untuk beroperasi dan harus meminjam kantor yang belum terpakai dan mengharuskan pindah jika kantor yang ditempati digunakan kembali oleh pemiliknya (http://mitranetra.or.id diakses pada tanggal 10 April 2019 pukul 11:35 WIB).

Berdasarkan latar belakang tersebut rumusan masalah utama dalam penelitian ini adalah Bagaimana interaksi simbolik pengajar musik tunanetra dengan siswa tunanetra di Yayasan Mitra Netra Lebak Bulus Jakarta Selatan. Dan bagaimana pengajar musik tunanetra mengatasi kendala yang terjadi dalam berkomunikasi dengan siswa tunanetra di Yayasan Mitra Netra. Tujuan penulis melakukan penelitian mengenai interaksi simbolik pengajar musik tunanetra dengan siswa tunanetra di Yayasan Mitra Netra Lebak Bulus Jakarta Selatan adalah Untuk mengetahui komunikasi interaksi simbolik pengajar musik tunanetra dengan siswa tunanetra di Yayasan Mitra Netra Lebak Bulus Jakarta Selatan. Dan untuk mengetahui cara pengajar musik tunanetra mengatasi kendala dalam pembelajaran bermusik di Yayasan Mitra Netra Lebak Bulus Jakarta Selatan. Karena penelitian mengenai interaksi simbolik antara pengajar tunanetra dengan siswa tunanetra dalam pembelajaran bermusik ini belum pernah ada yang meneliti.

\section{Metode Penelitian}

Dalam penelitian ini penulis menggunakan metode penelitian kualitatif secara deskriptif. Metode kualitatif menurut Strauss dan Corbin dalam buku Wiratna Sujarweni yang berjudul Metodologi Penelitian adalah jenis penelitian yang menghasilkan penemuan yang tidak diperoleh dengan menggunakan prosedurprosedur statistik atau cara-cara lain dari kuantifikasi atau pengukuran. Penelitian ini digunakan untuk penelitian tentang kehidupan masyarakat, sejarah, tingkah laku, 
fungsionalisasi organisasi, aktivitas sosial dan lain-lain (Sujarweni, 2014:19). Menurut Whitney dalam buku Moh. Nazir yang berjudul Metode Penelitian, metode deskriptif merupakan metode pencari fakta dengan interpretasi yang tepat dengan mempelajari masalah-masalah dalam masyarakat. Juga tata cara yang berlaku dalam masyarakat yaitu situasi-situasi tertentu termasuk tentang hubungan, kegiatankegiatan, sikap-sikap, pandangan-pandangan serta proses-proses yang sedang berlangsung dan pengaruh-pengaruh dari suatu fenomena (Nazir, 2011:54). Penulis menggunakan metode tersebut karena sejalan dengan perumusan masalah penulis yaitu bagaimana interaksi simbolik pengajar musik tunanetra dengan siswa tunanetra di Yayasan Mitra Netra Lebak Bulus Jakarta Selatan. Dan bagaimana pengajar musik tunanetra mengatasi kendala yang terjadi dalam berkomunikasi dengan siswa tunanetra di Yayasan Mitra Netra Lebak Bulus Jakarta Selatan.

Subjek penelitian penulis adalah pengajar musik tunanetra di Yayasan Mitra Netra yaitu Adi Ariyanto pengajar piano, Suryo Pramono pengajar angklung dan Oki Kurnia pengajar gitar, sekretaris sekaligus pengurus yaitu Muhammad Ahayar dan siswa yang belajar musik di Yayasan Mitra Netra.Data yang diperlukan penulis diperoleh berdasarkan metode pengumpulan data melalui observasi, wawancara dan studi pustaka. Lima narasumber yang diwawancarai oleh penulis yakni:

1. Adi Ariyanto selaku pengajar alat musik piano

2. Suryo Pramono selaku pengajar alat musik angklung

3. Oki Kurnia selaku pengajar alat musik gitar akustik

4. Muhammad Ahayar selaku sekretaris dan sekaligus pengurus Yayasan Mitra Netra

5. Abrar Ali selaku siswa yang belajar bermusik piano di Yayasan Mitra Netra

Untuk membuktikan keabsahan data dari penelitian ini, penulis menggunakan teknik pemeriksaan keabsahan data dengan teknik triangulasi.Menurut Patton dalam buku Lexy J. Moleong yang berjudul Metode Penelitian Kualitatif dikatakan bahwa triangulasi dengan sumber data berarti membandingkan dan mengecek balik derajat kepercayaan suatu informasi yang diperoleh dan alat yang berbeda dalam penelitian kualitatif (Moleong, 2014:330).

\section{Hasil Temuan dan Diskusi}

Berdasarkan wawancara dengan Muhammad Ahayar, komunikasi yang digunakan di Yayasan Mitra Netra tergantung pengajar masing-masing disesuaikan dengan perasaan nyaman anak tunanetra. Umumnya, komunikasi yang digunakan adalah dengan komunikasi verbal seperti bahasa dan simbolik serta komunikasi non verbal berupa sentuhan. Terdapat tiga pengajar musik yang memberikan pengajaran alat musik yaitu Adi Ariyanto pengajar piano, Suryo Pramono pengajar angklung dan Oki Kurnia pengajar gitar akustik yang memiliki perbedaan dalam gaya komunikasi dalam proses pembelajaran bermusik.

Adi Ariyanto selaku pengajar alat musik piano mengatakan bahwa komunikasi yang ada di Yayasan Mitra Netra Lebak Bulus Jakarta Selatan berupa komunikasi secara bolak-balik antara pengajar dengan siswa bahkan sebaliknya, interaksi, metode ceramah dan pembimbingan atau sharing. Tetapi tidak semua materi itu diterapkan terkadang berdiskusi antara siswa dan pengajar sepanjang materi dengan sesama siswa. Dan ada juga yang jarinya dipegang untuk mengarahkan menekan alat musik jadi lebih ke interaksi dan sentuhan. 
Suryo Pramono selaku pengajar alat musik angklung di Yayasan Mitra Netra mengatakan komunikasi yang digunakan dalam proses pembelajaran angklung berupa pengulangan suara melalui pendengaran. Ia selanjutnya memberikan instruksi secara lisan yang kemudian dipraktekkan oleh siswa melalui perabaan. Sebab tidak mungkin menggunakan visual karena siswa dan pengajar di Yayasan Mitra Netra merupakan tunanetra.

Oki Kurnia selaku pengajar alat musik gitar akustik di Yayasan Mitra Netra mengatakan bahwa komunikasi yang digunakan berupa perabaan dan pengulangan suara dengan mengikuti atau pengulangan dengan memberikan gitar pada siswa. Kemudian bagaimana posisi gitarnya, bagaimana memegang gitar yang benar biasanya Oki memegang tangan siswa untuk mengikuti gerak tangannya. Setelah itu siswa harus mendengarkan dan mempraktekkan.

Berdasarkan wawancara dengan Adi Ariyanto mengatakan bahwa kendala yang terjadi dalam pembelajaran piano adalah siswa sulit memahami pembelajaran yang diberikan dengan cara yang pengajar terapkan. Maka pengajar harus selalu mencari cara baru yang lebih efektif hingga siswa mengerti. Seringkali pengajar merasa kesal karena siswa tidak bisa menangkap materi yang disampaikan. Dengan begitu pengajar akan menyesuaikan cara mengajar dengan masing-masing kemampuan siswa. Pengajar tidak boleh menganggap siswa bodoh, nakal, dan kurang berbakat karena kemampuan memahami materi setiap anak berbeda-beda. Mengatasi kendalanya adalah pengajar harus memiliki sudut pandang yang berbeda. Seperti jika pengajar longgarkan pembelajaran yang diberikan, siswa akan sedikit tidak patuh. Berarti pengajar harus lebih disiplin, lebih ketat dan punya otoritas lebih agar siswa bisa patuh.

Suryo Pramono mengatakan dalam pembelajaran angklung kendalanya adalah dimulai ketidaktahuan siswa tentang musik sampai ke pribadi atau emosi siswa. Pemain musik angklung kadang egois karena angklung merupakan kelompokmusik. Jadi jika ada salah satu yang ingin terlihat dominan akibatnya lagu yang dimainkan akan terdengar tidak bagus. Dan bagaimana pengajar harus memberi arahan ke semua pemain angklung agar bisa kompak sampai keseluruhan. Mengatasi kendalanya adalah dengan cara komunikasi. Misalkan dari ketidaktahuan seperti jika tidak mengerti memainkan angklung pengajar akan menunjuk siswa lain yang sudah bisa main angklung untuk mengajarkan terlebih dulu siswa yang belum bisa bermain angklung. Maknanya untuk menjalin komunikasi antara sesama siswa, Membangun rasa kepercayaan diri dari yang mengajarkan bahwa siswa tunanetra masih bisa mengajarkan dan ada kebanggaan di dalam dirinya. Kemudian yang baru belajar musik juga pasti akan merasa diperhatikan. Dengan begitu cara mengatasi kendala adalah dengan komunikasi karena bagian dari rehabilitasi.

Oki Kurnia mengatakan bahwa dalam pembelajaran alat musik gitar kendalanya adalah jari siswa selalu menyentuh pembatas pada gitar dan posisi jari kurang penekanan pada senar gitar. Cara mengatasi kendalanya adalah dengan melakukan pengulangan dalam komunikasi agar siswa paham.

Berdasarkan wawancara penulis dengan Adi Ariyanto, mengatakan bahwa jenis komunikasi dalam pembelajaran piano di Yayasan Mitra Netra adalah melalui perabaan dan interaksi.

Suryo Pramono mengatakan proses pembelajaran angklung di Yayasan Mitra Netra dapat dilakukan melalui perabaan, sentuhan dan bahasa. Tidak visual karena pengajar musik dan siswa merupakan tunanetra. 
Oki Kurnia memperjelas bahwa jenis komunikasi dalam pembelajaran gitar di Yayasan Mitra Netra berupa interaksi, perabaan, sentuhan dan pengulangan suara.

Penulis mengamati salah satu komunikasi yang terjadi di Yayasan Mitra Netra yaitu komunikasi Interaksi Simbolik berupa sentuhan, perabaan dan bahasa. Sentuhan dan perabaan yang digunakan dalam proses pembelajaran musik di Yayasan Mitra Netra dilakukan karena pengajar dan siswa merupakan tunanetra. Dengan hal ini untuk menciptakan dan menghasilkan makna penggunaan simbol sangat penting diimplikasikan di dalam proses belajar musik. Siswa dan pengajar tidak menggunakan visual karena faktor ketunanetraan.

Dengan begitu bahwa komunikasi interaksi simbolik terjadi antara pengajar musik dengan siswa tunanetra dan sebaliknya. Adanya interaksi simbolik berupa simbol, sentuhan dan bahasa memungkinkan dalam merespon kegiatan untuk penyampaian maksud dalam penyampaian makna antara pengajar musik tunanetra dengan siswa tunanetra. Hal ini memudahkan jalannya komunikasi yang tercipta dalam mendapatkan umpan balik dengan sesama tunanetra.

Dengan adanya interaksi simbolik yang terjadi di Yayasan Mitra Netra Lebak Bulus Jakarta Selatan. Berupa simbol-simbol, sentuhan, perabaan dan bahasa dapat memudahkan pertukaran pesan dan pemberian makna dalam pembelajaran musik yang diberikan. Tujuannya untuk mempermudah dalam berinteraksi sosial dan menjalin komunikasi baik dengan sesama maupun dengan orang awas. Dulu tunanetra sulit dalam belajar dan beradaptasi karena saling menutup diri, sekarang dengan adanya berbagai macam pembelajaran yang membantu tunanetra dalam belajar serta penguatan diri memudahkan penyandang tunanetra dalam melakukan segala hal. Dengan adanya interaksi simbolik tersebut dapat menjadi bentuk komunikasi utama yang digunakan di Yayasan Mitra Netra Lebak Bulus Jakarta Selatan.

\section{Simpulan}

Penulis menyimpulkan beberapa kesimpulan yang menjadi hasil dari penelitian penulis sebagai berikut:

a. Di Yayasan Mitra Netra Lebak Bulus Jakarta Selatan memiliki tiga orang pengajar musik yang merupakan penyandang tunanetra. Yaitu Adi Ariyantopengajar piano, Suryo Pramono pengajarangklung dan Oki Kurnia pengajargitar akustik. Pengajar tersebut mengajarkan siswa tunanetra dalam pembelajaran bermusik di Yayasan Mitra Netra.

b. Komunikasi dan perabaan membantu pengajar musik tunanetra dan siswa tunanetra dalam pembelajaran bermusik di Yayasan Mitra Netra. Interaksi dan perabaan antara pengajar musik kepada siswa dapat menghasilkan makna dalam proses pembelajaran yang berlangsung di Yayasan Mitra Netra.

c. Dalam berkomunikasi menggunakan interaksi simbolik berupa perabaan, dilakukan dengan cara jari siswa dipegang untukmengikuti gerak tangan pengajar musik. Setelah itu siswa harus mendengarkan dan mempraktekkan pembelajaran yang diberikan oleh pengajar musik.

d. Kendala pengajar musik piano diatasi dengan cara tegas dan lebih disiplin agar siswa bisa patuh jika siswa yang diajarkan tidak patuh. Pengajar musik angklung mengatasi kendalanya adalah dengan berkomunikasi untuk membantu ketidaktahuan karena merupakan bagian dari rehabilitasi. Pengajar 
musik gitar mengatasi kendalanya dengan cara pengulangan dalam komunikasi agar siswa yang diajarkan dapat mengerti.

e. Komunikasi interaksi simbolik yang terjadi antara pengajar musik tunanetra dengan siswa tunanetra di Yayasan Mitra Netra Lebak Bulus Jakarta Selatan adalah menggunakan pengulangan suara melalui pendengaran, dan interaksi simbolik berupa perabaan. Sebab tidak menggunakan visual karena siswa dan pengajar di Yayasan Mitra Netra merupakan tunanetra. Dengan demikian komunikasi yang digunakan adalah komunikasi verbal berupa komunikasi secara lisan dan interaksi simbolik berupa perabaan.

\section{Ucapan Terima Kasih}

Penulis mengucapakn rasa terima kasih yang sebesar-besarnya kepada seluruh pihak yang telah membantu dan mendukung penulis selama proses penelitian ini berlangsung sampai dengan terbitnya publikasi atas hasil penelitian ini.

\section{Daftar Pustaka}

Hidayat, Asep AS dan Ate Suwandi. (2016). Pendidikan Anak Berkebutuhan Khusus Tunanetra. Jakarta: PT. Luxima Metro Media

http://mitranetra.or.id

Nazir, Mohammad. (2011). Metode Penelitian. Bogor: Ghalia Indonesia

R. Wirjana, Bernardine. (2009). Pelayanan Sosial Bagi Anak-anak Cacat. Jakarta:

Komunitas Pegiat Sosial Jakarta

Somantri, Sutjihati. (2009). Psikologi Anak Luar Biasa. Bandung: PT Refika Aditama

Sujarweni, V. Wiratna. (2014). Metodologi Penelitian. Yogyakarta: Pustaka Baru Press

Supradewi, Ratna. (2010). Otak, Musik dan Proses Belajar. Jurnal Buletin Psikolog. 